\title{
Changing the innovation landscape in the UK's National Health Service to meet its future challenges
}

This article was published in the following Dove Press journal:

Innovation and Entrepreneurship in Health

10 September 2015

Number of times this article has been viewed

\author{
James G Barlow \\ Department of Management, Imperial \\ College Business School, London, UK
}

Correspondence: James G Barlow Department of Management, Imperial College Business School, London, SW7 2AZ, UK

Tel +442075945936

Email j.barlow@imperial.ac.uk

\begin{abstract}
The UK's National Health Service is widely held to be lagging behind the health systems of other countries in its innovativeness. In particular, there is said to be a "technology deficit" in certain clinical areas, such that patients are unable to access the latest drugs or medical devices. Moreover, the UK conducts world-leading research in health-related sciences and has a globally competitive pharmaceutical industry and sizeable medical technology sector, yet there have been persistent concerns about the translation of this research into products that can be commercialized. The last 15 years have seen successive attempts to rectify this situation and improve the flow of health care innovations into practice. In addition, the importance of organizational innovation to improve productivity and clinical, quality, and safety performance has been recognized. This is becoming more urgent given the need to meet the challenges of rising demand for health care at a time of increasingly constrained resources. This review discusses the changing landscape of policy and other interventions that have been put in place to tackle the factors that inhibit health care-related innovation in the UK.
\end{abstract}

Keywords: health care, policy, medical technology, pharmaceuticals, research translation

\section{Introduction}

The UK's National Health Service (NHS) is facing a future shortfall in funding compared to the health care needs of the population. Annual expenditure has been frozen at approximately $\$ 205$ billion. Currently, the gap between available resources and needs is officially estimated to be between $\$ 12$ billion and $\$ 47$ billion in 2020/2021, depending on the NHS's ability to improve efficiency and achieve cost savings. ${ }^{1}$ Without innovation, ranging from new organizational and service-delivery models supported by technology to large-scale transformations such as integrated care, it will be extremely hard to tackle the funding gap, let alone meet the demands of an aging population and achieve world class standards.

The history of innovation in the UK's health care sector has been a troubled one. The UK has a world leading research base in science and technology, world leading biopharma firms, and a sizeable medical technology sector. But it is often argued that within the NHS there is a "technological deficit". Relative to other countries, there is said to be considerable ground to make up in the adoption of innovative technologies and processes in parts of the NHS. The health service as a whole has been characterized as "islands of excellence" surrounded by a "sea" of moderate to poor performers. ${ }^{2}$ In fact, it is by no means clear that the UK is especially backward in adopting health care innovations. Although they are methodologically limited, international comparative 
health care innovation indices by Go and Batra ${ }^{3}$ and $\mathrm{PwC}^{4}$ place the UK alongside France, Germany, and Japan.

Over the last 15 years, successive attempts have been made to rectify this situation by rebalancing the supply and demand sides for health care innovation, while also strengthening the research and industrial base for health care in the face of growing global competition. This paper reports on these policies and other initiatives, and their impact on the innovativeness of the NHS.

The paper first discusses the inbuilt structural and organizational features of the NHS which have inhibited its innovativeness in the past. It then outlines the evolving policy changes that are being put in place to address these problems. There are some differences between the way the NHS is organized in the four constituent nations of the UK; this review focuses only on NHS England.

\section{The structural barriers to innovation in the NHS}

Health care is frequently described as a "complex system" because of the presence of many interdependencies between its constituent parts. Changes in one part can trigger changes elsewhere, often with counterintuitive consequences. ${ }^{5}$ Lines of communication and spheres of responsibility are messy, professional and financial silos are common, and the economics of innovation are often unpredictable and perverse.

The NHS is no exception. The system was reorganized by the Health and Social Care Act 2012. This was designed to achieve a more rational model, channeling the bulk of funding to the parts of the system working within the primary care: general practitioners (GPs). Approximately two-thirds of its annual $\$ 150$ billion budget (England only) goes to 211 "clinical commissioning groups" (CCGs). These are led by GPs and commission services from hospital trusts, community and mental health services, and the private and voluntary sectors. There are 155 hospital and other trusts. Because of the central role of GPs in CCGs, to avoid a conflict of interest all GP services are commissioned by a national body: NHS England. Public health was once the territory of the NHS but has now been moved to local authorities and another national body: Public Health England. Local authorities are also responsible for "health and wellbeing boards", which bring together key players in the local health and social care system. There has been much less change among providers of care - the structure of GPs and hospital trusts remains as it was before the 2012 Act, although the latter have seen increasing freedoms to control their own budgets. The structure of the NHS - multiple autonomous organizations within a national framework - therefore ensures that the attributes of a complex system are clearly manifested. In particular, economics, organizational structures and behavior, and characteristics of knowledge sharing all impact on the NHS' capacity for innovation.

\section{The economics of health care innovation}

An important disincentive to the adoption of some health care innovations is that the costs and benefits are often disconnected. Organizational fragmentation within the NHS and social care systems means that "silo budgeting" is the norm. The primary, secondary, and social care systems remain largely financially autonomous, although the reforms under the Health and Social Care Act 2012 and recent moves toward the delivery of some integrated services have tried to address this situation. Silo budgeting means that the benefits of an innovation may accrue to a budget holder who is separate from the one bearing the investment costs.

Second, the time taken for the benefits of innovations to be realized - especially ones that are complex and involve multiple organizations - can be long. In the longer-term, an innovation might be cost-saving to the NHS, but the short-term transition costs associated with its implementation are often unfunded. This is especially the case for preventative interventions, seeking to reduce patient referrals across the health care system. However, NHS health trusts (which provide health care services) are restricted by the annual budgetary cycle and limited in their ability to accumulate discretionary funds or generate a financial surplus.

These financial features of the NHS therefore leave little room for investment in innovations that may require significant upfront expenditure or involve a contribution from different departmental budgets. The focus of NHS management at a local level tends to be on initial costs, so expensive innovations are less likely to be adopted even if they may have significant benefits further down the line. The result is a short-term outlook and generally risk-averse behavior, which is a barrier to the adoption of new practices. Added to this problem are the uncertainties over the future NHS landscape. The widely held perception is that policy shifts are frequent, leading to a fear that investment in innovative new practices maybe undermined.

An example of effects of NHS economics on innovation is the introduction of telecare/telehealth (the remote monitoring of vital signs or activities of daily living) for frail elderly people or those with long-term chronic conditions. Effective communication and collaboration between different professional teams that span the somewhat artificial 
divide between health and social care are essential for providing good quality care to this population, but this has often proved hard in a fragmented care system. These challenges are multiplied, however, when telecare/telehealth $-\mathrm{a}$ complex innovation combining technological and organizational change - is involved. The costs, risks, and benefits associated with this innovation are spread unevenly across the care system and there may be counterintuitive effects, for example, where reduced demand for hospital beds from frail elderly people is offset by an increase in the volume of more expensive elective surgery patients. ${ }^{6}$

The NHS system of payment and reimbursement for medical procedures can also cause problems for innovation. NHS trusts are paid for their activity according to a tariff system, based on the average cost of a group of procedures. This is based on current practice and does not generally subsidize the cost of innovative, and possibly more expensive, procedures that would improve quality over time. Moreover if an innovation improves efficiency by reducing activity, an NHS trust may be penalized because it will receive less under the tariff system. Another problem is that trusts do not have accurate costing systems giving them detailed information on what they pay per patient to provide a service. This means that they struggle to identify potential savings, giving them less reason to drop outdated practices and adopt new ones.

\section{Organizational fragmentation}

\section{Selling is hard}

Organizational fragmentation impacts on the procurement process for new technologies, as well as causing the problems associated with silo budgeting. The quality of engagement between purchasers and suppliers is important in influencing the adoption of technology, but for health care technology companies the perceived market opportunities within the NHS are often seen as unattractive. Problems include the diversity of buying points, extended and complex procurement processes, and a tendency for NHS organizations to focus on "lowest cost" rather than "best value" when weighing up the potential benefits of an innovation. This is compounded by the fact that within NHS organizations there is usually no individual with the job of scouting systematically for innovations, as found in leading private sector companies. In short, for medical technology companies, the landscape can be difficult to navigate (although for the biopharma section the process for introducing of new drugs is far more structured and regulated).

Technology suppliers need to provide a business case in terms relevant to an NHS purchaser, while the NHS needs to provide suppliers with information about its needs. However, the devolved nature of the NHS, in which management responsibility is delegated to individual organizations, presents particular problems to companies selling new technologies. Individual NHS organizations have considerable freedom to determine their own approaches and requirements against which they assess technology business cases. A business case for a particular technology may satisfy the requirements of one NHS trust, but not another, creating confusion for suppliers, who often receive little guidance on how best to meet the requirements. There have been particular concerns about the creation of business cases, especially where an innovation is more complex with impacts across different parts of the care system. To be able to make a clear case for investment, health trusts need information about outcomes, value for money, and the impact on patient experience, but they generally lack the skills and resources to identify and compare different options. On the other hand, companies wishing to sell technological innovations, especially those producing new medical devices, are often small and also lack the skills and resources to do the necessary economic modeling.

A common complaint therefore is that the cost of sale to the NHS is too high, deterring smaller suppliers. For some technologies, NHS trusts are partners in collaborative procurement organizations where they can share information and resources to achieve economies of scale, but this is not the norm for the majority of new technological innovations.

\section{Too many trials and pilot projects}

Innovations need to demonstrate unambiguous relative advantages over existing technologies, products, or practices. Evidence for costs and benefits is therefore important in decisions about whether to commit resources to an innovation. In principle, the system designed to assess, trial, and encourage the spread of new technologies acts as a filter and catalyst for the adoption of new technology. As resources within the NHS are finite, there is clearly a need to control the introduction of new technologies based on their relative clinical and cost-effectiveness, along with a desire to practice evidencebased medicine.

Some medical innovations - largely new drugs and treatments - are assessed by the National Institute for Health and Clinical Excellence (NICE). These assessments are used to provide national guidance on technology purchasing. The NHS is legally obliged to fund medicines and treatments recommended by NICE. However, this does not automatically lead to implementation, partly because of a lack of clarity 
about which body is responsible for ensuring implementation. Although the quality and rigor of health technology assessments from NICE are widely praised, the selection of innovations that are assessed is limited. This means that adoption decisions about new technologies not assessed by NICE are left to the local level, resulting in geographical differences in their availability. Another concern is that NICE economic evaluations are too narrow and do not consider the wider benefits of an innovation to society.

There are particular issues relating to the collection and interpretation of evidence within health care. A bias toward scientific fact and a positivist epistemology in the evaluation of new innovations can lead to a view that anything short of the randomized controlled trial - the gold standard of evidence - lacks credibility. Complex health care innovations involving multiple interventions to modify a service are not usually amenable to this approach, meaning that their evidence base is usually less clear-cut. There is concern that too much emphasis on "evidence" can stifle the adoption of such innovations and a more pluralist approach is needed.

Given the potential implementation costs and ambiguities in benefits, health care organizations often look more favorably on innovations that can be introduced on a trial basis. Trials and pilot projects can reduce the risk and increase the visibility of an innovation's benefits, thereby contributing to its evidence base. They can also provide useful lessons for implementation and scaling-up the innovation should it prove successful in the trial. However, a problem frequently highlighted in the NHS is the excessive repetition of trials of the same innovation across different NHS trusts. According to one commentator, "Pride can also prevent adoption of innovation - 'not invented here' is ... rife in the artificial kingdoms created in the NHS". ${ }^{7}$ Despite this replication of trials and pilot projects, findings from a large proportion of them never see the light of day.

While they can deliver useful information, trials and pilot projects may themselves act as a barrier to the adoption of a technology because they can hold up the larger-scale implementation of an innovation. This occurred with the Whole System Demonstrator program, a large-scale pilot for telehealth and telecare which included the world's largest randomized control trial of this type of innovation. It is thought that many NHS trusts and local social services authorities held back from implementing the technology more widely until the program of research was finished and published, although others believed that the evidence base was sufficiently robust to allow them to move forward. ${ }^{8}$

\section{Organizational capacity and leadership for innovation}

An organizational culture that encourages innovation is influenced by strong leadership, a clear strategic vision, and collective attitudes that are conducive to experimentation. ${ }^{9,10}$ Achieving this within the NHS has proved problematic, partly because of a tradition of top-down central control, hierarchical decision-making, and extensive overlapping demands from regulators and performance managers.

Effective leadership involves acknowledging the challenges, supporting managers and medical staff involved in innovation, and fostering learning through trial and error without the fear of penalties. However, NHS managers are not judged by how innovative they are; they are judged by how well they stay within their budget and carry out the tasks demanded of them. Another concern is the availability of management resources. The large number of initiatives competing for managers' time makes it hard to free the organizational resources required to manage the implementation of some innovations. The bulk of public funding for health care innovation is for research and development, with little available for implementation into health services.

\section{Knowledge transfer and communications}

The influence and membership of professional and social networks can determine how well new knowledge spreads and creates normative and institutional pressures for adoption. ${ }^{11}$ Innovations will spread most effectively if the flow of information about them is free and efficient, so that potential buyers and users know about potential benefits and how to implement them. Gaps in the awareness of innovations can arise because information about them is in a form that is not easily understood or because implementation requires knowledge that can only be gained through direct contact with others who have implemented the innovation. Rigid delineation between professional networks within health care may limit the spread of innovation if important stakeholders are excluded, so the configuration of knowledge networks is important.

One important way in which knowledge of innovations can be spread within health care is through individuals, such as clinicians or service commissioners, who champion an innovation. There are different forms of innovation champion but one important role they have is to act as boundary spanners, bridging the various fragmented parts of the NHS. ${ }^{12}$ Clinical reputation is an important currency in the NHS and can form the basis of efforts to spread innovation and best practice. ${ }^{13}$ Opinion leaders are important because they have a 
strong influence on the beliefs and actions of their colleagues. These may not be the initial enthusiasts for an innovation but are the senior professionals who throw their authority and status behind it, based on their expert judgment.

Professional networks, both organized and informal, are another means of supporting the spread of information about innovation within the NHS. There are different forms of network in health care, with differing implications for the adoption of innovation. Doctors tend to have informal horizontal networks that are effective at spreading peer influence and constructing and reframing the meaning of innovations. Other groups, such as nurses, tend to have more formal, vertical networks, which are effective at transferring codified information and passing on decisions from higher authority. ${ }^{14}$ Innovations that require different professional groups to work together or originate outside a particular group can find it harder to win the necessary support, and it can require considerable effort to create effective multidisciplinary networks or communities of practice.

\section{The evolving policy landscape}

At the time of the NHS Plan, a major review of health services in the UK published in 2000, there was little emphasis on the role of innovative technology in meeting future health care needs. The Plan referred only fleetingly to the potential of innovative technology to transform care delivery. ${ }^{15}$ Subsequent reports by the Health Select Committee ${ }^{16}$ and the Healthcare Industries Task Force ${ }^{17}$ expressed concern about the slow adoption of new technology and made recommendations designed to speed up innovation and promote a better working relationship between the NHS and industry. The latter included proposals to strengthen the NHS procurement process. Other initiatives at the time were designed to ensure the UK remains at the forefront of health research and a location of choice for the pharmaceutical sector. "Best Research for Best Health" ${ }^{18}$ was established to speed up the transfer of research findings into treatment and the UK Clinical Research Collaboration was designed to improve the infrastructure for clinical and medical research.

By the mid-2000s the picture was therefore mixed. Some parts of the NHS were research- and innovation-friendly, particularly ones with strong links between universities and hospitals. But the capacity of the wider NHS to adopt new ideas and technologies was increasingly seen as a serious hindrance to its future development. There was particular concern that the UK was at risk of failing to reap the full economic, health, and social benefits that the substantial public investment in health research should generate. In 2006, the government therefore set up a major independent review to advise on future institutional arrangements for supporting health research and innovation in the UK.

The Cooksey review ${ }^{2}$ identified the presence of two key gaps in the translation of health research into NHS practice: translating ideas from basic and clinical research into the development of new products and approaches (the "first translation gap"); and implementing new products and approaches into clinical practice (the "second translation gap"). The review found that the funding arrangements for supporting research translation were insufficiently coherent and comprehensive, and did not function well. The review identified a range of issues relating to the culture and economics of the NHS that limit the translation of research into health and economic benefits. These included a conservative approach to new ideas and technologies; lack of standard routes into the NHS for new technologies, especially those developed by smaller medical technology companies; and a tendency by managers to see innovation primarily as a pressure on costs, without looking at its potential for longer-term efficiency gains.

The policy emphasis at this time was largely on "push", ie, technology development and supporting research and development, rather than "pull", stimulating demand from clinical or health services. However, there were some efforts underway to address the problem of spreading knowledge and raising the capacity of NHS organizations to become more innovative. The NHS Modernisation Agency had already been established to spread innovation and best practice in health service management and delivery. Its role was subsequently taken over by the National Institute for Innovation and Improvement, but despite progress in some trusts and in some areas of practice, commentators remained concerned that it was not possible to drive such changes through centralized initiatives and it would be necessary to change the structure of incentives within the NHS to influence the take-up of innovation and best practice.

Parallel to the Cooksey report, the NHS Next Stage Review ${ }^{19}$ reiterated the importance of technological innovation for the NHS and set out aspirations and regional plans for delivering it. ${ }^{20}$ This placed a legal duty on NHS strategic health authorities to promote innovation.

Together, these policy activities set the scene for the current health care innovation landscape and subsequent attempts to again change the configuration of institutional and funding arrangements. The inherent structural and organizational barriers to innovation in the NHS described earlier are being tackled in various ways. 


\section{Incentivizing innovation through payment for health services}

The economics of innovation are being influenced by measures which influence the way payment for services takes place. However, none of the levers described here are coordinated with the rest of the innovation and improvement infrastructure.

The Quality and Outcomes Framework (QOF) measures and financially incentivizes good practice among GPs. A wide range of indicators of clinical care, organizational approaches, patient experience, and provision of additional services are included within QOF. Second, the system of block contracts in the secondary care sector is being replaced by Payment by Results, an activity based payment system with tariffs based on national average costs, adjusted for casemix. The tariff rewards providers for increasing productivity, encouraging them to improve efficiency and control of costs. It also incentivizes high-quality care by paying a higher tariff price: the Best Practice Tariff. A number of Best Practice Tariffs have been established in different clinical areas, such as acute stroke care or hip and knee replacements. Concerns have been raised over the use of Payment by Results and Best Practice Tariffs, notably over the quality of cost information on which the tariff is based. ${ }^{21}$ One report ${ }^{22}$ found that unit costs differ substantially between providers, with no clarity on whether this is due to real differences in costs or differences in allocation of costs or data collection.

Another form of pay for performance is the Commissioning for Quality and Innovation (CQUIN) scheme, introduced in 2009 to "support a cultural shift to make quality and innovation part of the commissioner-provider discussion everywhere" ${ }^{23}$ CCGs - which purchase a majority of health care services in the NHS - play an active role in developing CQUIN goals for each provider. The system makes a proportion of a health care provider's annual income conditional on reaching quality targets agreed between the commissioner and provider. Most of these targets are agreed locally, but there are also a limited number of national and regional targets around safety, effectiveness, patient experience, and innovation. The proportion of the provider's income that is conditional on achieving the CQUIN target grew from $0.5 \%$ in 2009 to $2.5 \%$ in 2012 .

One evaluation of CQUIN ${ }^{24}$ concluded that while it has helped commissioners and providers to identify and prioritize local needs for quality improvement, the impact on quality has been minimal. Several problems were identified, including clinician dissatisfaction over the way CQUIN goals were developed and unclear and imprecise outcome measures, which emphasize processes rather than clinical outcomes. Freedom to use local indicators, though potentially useful for engaging clinicians, has also resulted in a lack of standardized outcome measures. The short-term nature of the CQUIN goals was also found to limit the motivation for trusts to make investment in measures to improve performance.

\section{Tackling organizational fragmentation}

The impact on the landscape for innovation of the changes to the organization of the NHS system is described earlier. While the principle of channeling the largest proportion of NHS funding from government to local providers via CCGs is sound, since they evaluate local needs and plan and purchase services, the reforms under the 2012 Act have not addressed the problem of organizational fragmentation. There are over 200 CCGs, more than the number of primary care trusts they replaced, and over 150 hospitals and other trusts providing services. A growing number of the latter are "foundation trusts" with more freedom to control their own budgets. The problem of financial silos therefore remains. Although government policy has increasingly advocated an integrated care approach to the design of services ${ }^{25}$ - bringing together local CCGs, NHS trusts, social services, and the voluntary sector - and a program of "pioneer" schemes is currently being implemented, planning and sharing budgets for integrated care services is proving to be hard. Nonetheless, some CCGs have begun experimenting with new approaches to commissioning, such as the use of prime and alliance contracts, as a way of driving more integrated care. ${ }^{26}$ These potentially enable clients - ie, CCGs - to specify performance or innovation requirements within the contract.

\section{Procurement}

In response to the Healthcare Industries Task Force report, ${ }^{17}$ various supporting initiatives were set up to encourage the adoption of technology. The NHS Technology Adoption Centre was established to promote greater cooperation between organizations involved in the development and use of health care technologies. It worked with the health care technology industry to help improve understanding of the processes and requirements necessary to sell products to the NHS. Subsequently, the NHS Technology Adoption Centre was absorbed into the NHS National Innovation Centre, which aims to speed up the development of precommercial technologies. ${ }^{27}$ Regional innovation hubs ${ }^{28}$ were also set up to offer legal and commercial support specifically to NHS staff with a premarket product. Another body, NHS Improving 
Quality, ${ }^{29}$ was established in 2013 as the coordinating body for improvement across NHS England. This is focusing its attention on initiatives which target the five domains of the NHS Outcomes Framework.

\section{Knowledge transfer and communications}

There has been considerable activity to establish local organizations which coordinate stakeholders from across the health system to support innovation and service change. An important function of these bodies is to create a "pull" for innovations by ensuring that the flow of knowledge is optimized, and a market for its adoption is created among health care providers and commissioners.

Fifteen "Academic Health Science Networks" (AHSNs) ${ }^{30}$ were established in 2013 to provide a means for providers to work together at a regional level to support innovation and service change, and improve the translation of research into practice. The AHSNs support knowledge exchange networks and rapid evaluation to promote the early adoption of innovations, and coordinate a program to connect health sector challenges with innovative ideas from industry by funding competitions (the Small Business Research Initiative). ${ }^{31}$ Essentially, AHSNs are integrators to link different parts of the local health ecosystem across traditional boundaries.

While AHSNs are very much about spreading innovation, the focus of "Collaborations for Leadership in Applied Health Research and Care" (CLAHRC) ${ }^{32}$ is largely on operationalization. The CLAHRCs are partnerships between universities and surrounding NHS organizations, and seek to improving patient outcomes by addressing the "second translation gap" identified the Cooksey report. ${ }^{2}$ By 2014, 13 CLAHRCs had been established, each with a slightly different slant - some are more focused on applied health research and others on the application of improvement science to the delivery of health care.

Innovation by GPs has long been a neglected area, both in policy and research. The creation of CCGs under the recent reforms has provided GP practices with increased freedom to determine which innovations are relevant to their services. However, there is a risk that innovation will not be a priority for practices coping with wider institutional shifts. A recent review $^{33}$ found that the majority of practices adopted the QOF measures by the time they were issued, but the process of adopting innovations within the GP sector is extremely variable.

It is widely felt that CCGs should have a role in assembling and supporting local GP knowledge networks. New federations and networks which are being developed by
GP providers need strong clinical leadership, but concerns about conflicts of interest (because a CCG both commissions services in primary care and its GP members also provide them), mean that GP leaders have to choose between retaining a commissioning role or focusing on promoting innovations in the provision of health care.

The newly formed AHSNs could play a part here, given their objective of supporting the spread of innovation and bringing together stakeholders across sectors and institutions. It is too early to determine what progress AHSNs have made. However, since they face the challenge of simultaneously supporting, driving, and evaluating innovation, their room for maneuver may prove limited.

\section{The future}

Supporting new health care technologies through the innovation journey is seen as an important part of government policy in the UK, both to ensure evidence-based new ideas are taken up within the NHS and to stimulate the national health care technology and biopharma sectors. However, after a decade or more of reforms both to the broader structure of the NHS and to the landscape of organizations and initiatives designed to support innovation, there is now a complicated pattern of overlapping bodies and funding programs. These provide support across all the stages of the innovation process, from the various national Research Councils funding basic research to AHSNs and CLAHRCs designed to support adoption and diffusion, although there are still concerns about support for key parts of the innovation journey, notably the "valley of death" (the funding gap between demonstration of new technologies and larger scale trials prior to commercialization).

The health care innovation landscape is therefore comprehensively mapped. But this landscape remains hard to navigate. Not only are there many potential sources of support, but there are overlaps between the areas in the landscape occupied by AHNSs, CLAHRCs, and the six Academic Health Science Centres $^{34}$ (established in 2013 to tackle the "first translation gap") - all are tasked with helping to bring new ideas to mainstream use within the NHS. Over 20 bodies or funding initiatives are in place to support innovation in health care and there is still confusion for the developers of new health care technology about where to turn for support.

In October 2014, NHS England published its Five Year Forward View ${ }^{1}$ of the challenges it faces, highlighting the need to improve productivity in the health system. It set out various scenarios for transformational changes, but depending on the efficiency and funding option pursued, the effect would be to only partially close the $\$ 47$ billion gap over the 
next 5 years. Parallel to this, two further reviews on national health care innovation performance were announced. One of these, the Innovative Medicines and Medical Technology Review, ${ }^{35}$ will consider the pathway for the development and uptake of new medicines, diagnostics, and devices in order to speed up patient access. This is partly supported by the creation of a new joint ministerial post covering both health and business development. The second review is considering how improvement and leadership development works across the health and care system in England. ${ }^{36}$ This aims to ensure that various organizations involved in health care innovation - the NHS Leadership Academy and NHS Improving Quality, as well as strategic clinical networks and AHSNs - have a clear and simple purpose.

\section{Conclusion}

Transforming the NHS in a way that enables it to deal with future demand for health care in the face of constrained resources undoubtedly requires innovative thinking. The debate about how to reconfigure service delivery models is only just beginning. Questions such as the number of hospital beds needed in the future, and the role of technological and organizational innovation in shifting care from expensive settings into the community and home, remain open. While certain technological innovations such as telehealth have been shown to reduce hospital admissions and emergency care attendances, simply demonstrating in a trial that patients in acute beds could be cared for in alternative settings does not mean that capacity in the system outside hospitals exists - innovation around primary and social care is going to be needed but this is a neglected area, partly because of its complexity.

Lowering the barriers to adoption, embedding, sustaining, and spreading innovation in the NHS requires simultaneous moves on a number of fronts. The latest round of initiatives to strengthen the infrastructure that supports UK health care innovation is tackling the levers for performance improvement within the NHS. This should go some way to addressing the transformation agenda. The first and second translation gaps are being progressively closed through the actions of AHSNs, CLAHRCs, and other initiatives. In a system that increasingly places emphasis on evidence-based policy, the institutional basis for gathering, analyzing, disseminating, advocating, and monitoring what works is slowly improving. Changes to the financial incentives to adopt innovative technologies and processes may help, but the interactions between different parts of the health and social care systems - and the distribution of costs and benefits - remain an important inhibitor on innovation.

Health care also remains a deeply political arena, so seemingly rational innovations that have the potential to improve the productivity or quality of services can rapidly become the subject of populist disquiet; adoption is by no means guaranteed even if there is a proven evidence base. It can often be easier for NHS managers to say "no" to an investment in a health care innovation than to say "yes".

\section{Acknowledgment}

This report was commissioned by Innovation and Entrepreneurship in Health. No external funding or payment was involved in its preparation.

\section{Disclosure}

The author reports no conflicts of interest in this work.

\section{References}

1. The NHS Five year forward view [webpage on the Internet]. Redditch: NHS England. Available from: http://www.england.nhs.uk/ourwork/ futurenhs/. Accessed May 9, 2015.

2. Cooksey D. A Review of UK Health Research Funding. London: HM Treasury; 2006.

3. Go R, Batra N. Innovation Indicators for Healthcare in Emerging Countries - Understanding and Promoting Innovation in Emerging Markets. Deloitte; 2009.

4. PwC. Medical Technology Innovation Scorecard: The Race for Global Leadership. PricewaterhouseCoopers LLP; 2011.

5. Plsek PE, Wilson T. Complexity, leadership, and management in health care organisations. BMJ. 2001;323:746-749.

6. Bayer S, Barlow J, Curry R. Assessing the impact of a care innovation: telecare. Syst Dyn Rev. 2007;23:61-80.

7. Barratt C. The 7 deadly sins of NHS innovation [webpage on the Internet]. 2014. Available from: https://www.linkedin.com/ pulse/20140530085226-81796176-the-7-deadly-sins-of-nhs-innovation. Accessed May 9, 2015.

8. Chrysanthaki T, Hendy J, Barlow J. Stimulating whole system redesign: Lessons from an organizational analysis of the Whole System Demonstrator programme. J Health Serv Res Policy. 2013;18(1 Suppl): $47-55$.

9. Dopson S, FitzGerald L, Ferlie E, Gabbay J, Locock L. No magic targets! Changing clinical practice to become more evidence based. Health Care Manage Rev. 2002;27:35-47.

10. Ham C, Kipping R, McLeod H, Meredith P. Capacity, Culture and Leadership: Lessons from Experience of Improving Access to Hospital Services. Birmingham: Health Services Management Centre, School of Public Policy, University of Birmingham; 2002.

11. Rogers EM. Diffusion of Innovations. 5th ed. New York: The Free Press; 2003.

12. Hendy J, Barlow J. The role of the organizational champion in achieving health system change. Soc Sci Med. 2012;74:348-355.

13. Locock L, Dopson S, Chambers D, Gabbay J. Understanding the role of opinion leaders in improving clinical effectiveness. Soc Sci Med. 2001;53:745-757.

14. Ferlie E, Fitzgerald L, Wood M, Hawkins C. The Nonspread of Innovations: the Mediating Role of Professionals. Acad Manage J. 2005;48(1):117-134. 
15. Wanless D, Appleby J, Harrison A, Patel D. Our Future Health Secured? A Review of NHS Funding and Performance. London: King's Fund; 2007.

16. House of Commons Health Committee. The Use of New Medical Technologies Within the NHS: Fifth Report of Session 2004-2005. London: The Stationery Office Limited; 2005.

17. Strategic Implementation Group (SIG), Healthcare Industries Task Force. Innovation for Health: Making a Difference. London: Department of Health; 2007.

18. Department of Health. Best Research for Best Health: A New National Health Research Strategy: The NHS Contribution to Health Research in England. London: Department of Health; 2006.

19. Department of Health. Our NHS Our Future: NHS Next Stage Review - Interim Report. London: Department of Health; 2007.

20. Department of Health. High Quality Care For All: NHS Next Stage Review Final Report. Norwich: The Stationary Office; 2008.

21. Abma I, Jayanti A, Bayer S, Mitra S, Barlow J. Perceptions and experiences of financial incentives: a qualitative study of dialysis care in England. BMJ Open. 2014;4:e004249.

22. PwC. An Evaluation of the Reimbursement System for NHS-Funded Care: Report for Monitor. London: PricewaterhouseCoopers LLP; 2012. Available from: https:/www.gov.uk/government/uploads/system/ uploads/attachment_data/file/285988/Evaluation_Report_-_Full_ Report_FINAL.pdf. Accessed 9 May, 2015.

23. Department of Health. Using The Commissioning for Quality and Innovation (CQUIN) Payment Framework: Guidance on New National Goals for 2012-2013. London: Department of Health; 2009.

24. McDonald R, Zaidi S, Todd S, et al. Evaluation of the Commissioning for Quality and Innovation Framework: Final Report. 2013. Available from: http://hrep.lshtm.ac.uk/publications/CQUIN_Evaluation_Final_ Feb2013-1.pdf. Accessed May 9, 2015.

25. Department of Health. Our Health, Our Care, Our Say: A New Direction for Community Services. London: The Stationery Office; 2006.

26. Addicott R. Commissioning and contracting for integrated care [webpage on the Internet]. London: King's Fund; 2014. Available from: http://www.kingsfund.org.uk/publications/commissioning-contractingintegrated-care. Accessed May 9, 2015.
27. Knowledge and Information Zone [webpage on the Internet]. NHS National Innovation Centre; 2012. Available from: http://knowledge. nic.nhs.uk/. Accessed May 9, 2015.

28. NHS Regional Innovation Hubs [webpage on the Internet]. NHS National Innovation Centre; 2012. Available from: http://knowledge. nic.nhs.uk/orgDetails.aspx?orgId=4. Accessed May 9, 2015.

29. NHS Improving Quality (NHS IQ) [webpage on the Internet]. Leeds: NHS Improving Quality. Available from: http://www.nhsiq.nhs.uk/ about-us.aspx. Accessed May 9, 2015.

30. Academic Health Science Networks [webpage on the Internet] Redditch: NHS England. Available from: http://www.england.nhs.uk/ ourwork/part-rel/ahsn/. Accessed May 9, 2015.

31. NHS Confederation, TheAHSNNetwork. Cracking the Innovation Nut: Diffusing Healthcare Innovation at Pace and Scale. London: NHS Confederation; 2015.

32. CLAHRC Partnership Programme [webpage on the Internet]. London: CLAHRC Partnership Programme; 2014. Available from: http://www. clahrcpp.co.uk/. Accessed May 9, 2015.

33. Stokes K, Barker R, Pigott R. Which Doctors Take up Promising Ideas? New Insights from Open Data. London: NESTA; 2014.

34. Top NHS and university alliances recognized by Department of Health [webpage on the Internet]. London: govt.uk; 2013. Available from: https://www.gov.uk/government/news/top-nhs-and-university-alliancesrecognised-by-department-of-health. Accessed May 9, 2015.

35. Major investments in life sciences [webpage on the Internet]. London: govt.uk; 2014. Available from: https://www.gov.uk/government/news/ major-investment-in-life-sciences. Accessed May 9, 2015.

36. Reviewing improvement and leadership development capability across health and care in England [webpage on the Internet]. Redditch: NHS England. Available from: https://www.england.nhs.uk/ourwork/qualclin-lead/smithreview/. Accessed May 9, 2015.
Innovation and Entrepreneurship in Health

\section{Publish your work in this journal}

Innovation and Entrepreneurship in Health is an international, peer reviewed, open access journal publishing original research, reports, reviews and commentaries on innovation and entrepreneurship in health. Special focus will be given to the theory, process, and practice of innovation and entrepreneurship by individuals and organizations

\section{Dovepress}

within the health care context globally. The manuscript management system is completely online and includes a very quick and fair peer review system, which is all easy to use. Visit http://www.dovepress.com/ testimonials.php to read real quotes from published authors. 